\title{
Calibration of PVDF Film Transducers for the Cavitation Impact Measurement
}

\author{
Jan Hujer ${ }^{1, *}$, Miloš Müller ${ }^{1}$ \\ ${ }^{1}$ Technical University of Liberec, Dep. of Power Engineering Equipment, Studentska 2, 46117 Liberec, Czech Republic
}

\begin{abstract}
This paper describes investigation of the influence of the protective layer thickness on the calibration sensitivity of PVDF films sensors for the cavitation impacts measurements. The PVDF film sensor is casted into an aluminium block. The drop ball method is used for the measurement of the relation between impact force and the voltage detected on the PVDF film sensor. The calibration constants are measured for three different protective layers thicknesses. Five different ball weights for $400 \mathrm{~mm}$ drop height are used to reach the required impact force range. The ball positions for the evaluation of the impact force are measured with a high speed camera. The voltage signal detected on the PVDF film clamps was measured with a high speed digitizer. The measured signals are analysed in LabVIEW Signal Express.
\end{abstract}

\section{Introduction}

The cavitating flow appearing in hydraulic machines is usually associated with a noise, vibration, loss in the efficiency and cavitation erosion. These undesirable phenomena are connected with activities of cavitation bubbles or rather cavitation bubble structures - the bubble clouds. In the case of cavitation erosion, microjets and shock waves are formed during the final stage of the cavitation bubble cloud collapse. These effects interacts with near walls and causes the material damage.

The research focusing on the cavitation erosion covers mainly mass loss tests and pitting tests. During the test the material is undergoing cavitation load for a certain time period [1-2]. Another way how to study the cavitation erosion is to measure and count pulses due to impacts of microjets and shock waves by sensors mounted at exposed positions on the material. The piezoelectric transducers and especially thin piezoelectric polyvinylidene fluoride (PVDF) polymer transducers are applicable for these measurement. The very fast response of the PVDF transducers enables the measurement of impact forces of a high intensity and a short duration, which is just the case of impacts due to the cavitation bubble cloud collapse. During the cavitation erosion the mounted sensor is highly loaded by the cavitating flow. A protective layers of a resin or a tape are used to avoid the transducer damage. The presence of the protective layers can however influence the sensor sensitivity. Methods used to protect the PVDF films transducers are presented in the following text.

Momma et al. [3] counted pulses and measured their height by the $110 \mu \mathrm{m}$ thick PVDF film transducer with protection in cavitating jet apparatus. Authors tested effect of two, four and six protective layers of polyimide tapes on pulse height distribution. The output in all cases was indistinguishable.

Soyama et al. [4] used $110 \mu \mathrm{m}$ thick PVDF film transducer to count and measure pulses in cavitating jet apparatus. The sensor in this work was protected by $60 \mu \mathrm{m}$ thick polyimide tape.

Wang et al. [5] used $28 \mu \mathrm{m}$ thick PVDF film transducer to measure impact forces due to a single bubble collapses near a solid boundary. Authors protected used PVDF film transducer by a one layer of scotch tape. The measured sensitivity constant was $0,013 \mathrm{~V} / \mathrm{N}$.

Grinspan et al. [6] used $52 \mu \mathrm{m}$ thick PVDF film transducer protected by the cellophane tape. The sensor sensitivity of used design was $0,116 \mathrm{~V} / \mathrm{N}$.

In a case of very aggressive flow regimes or testing conditions, transducers need to be protected by higher number of protective layers. These could be made of glue. The aim of this study is to calibrate a $28 \mu \mathrm{m}$ thick piezoelectric PVDF film transducer for the cavitation impact load measurement in a vibratory cavitation apparatus. Another task is to evaluate the influence of a protective layer thickness on the sensor sensitivity.

\section{Calibration - ball drop method}

Three methods - a pendulum-typed ball impact method, ball drop method and lead breaking method are commonly used for the calibration of the PVDF film transducers [7]. The ball drop method was chosen for the calibrations in presented work. The scheme of the method is presented in Fig. 1.

A stainless steel ball of certain weight $m$ drops vertically from position 1 of height $h_{1}$ above the calibrated transducer, hits the calibrated transducer and rebounds to position 2 of height $h_{2}$ above the calibrated transducer. A plastic tube is used for the ball guiding. A camera and

\footnotetext{
* Corresponding author: jan.hujer@tul.cz
} 
a rule are used to measure the heights $h_{1}$ and $h_{2}$. During the impact, a part of the initial ball energy is transformed in a deformation of transducer which generates an electric charge. Electric charge is measured as an electric voltage output from which the maximum voltage $U_{\max }$ and the time duration of the impact $\tau$ are determined.

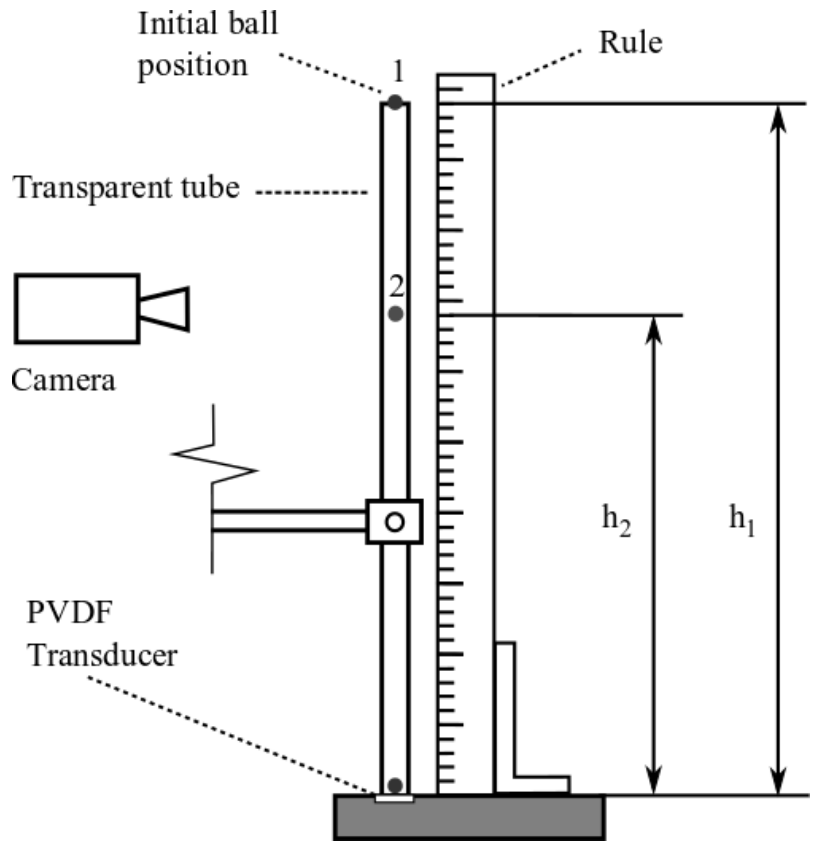

Fig. 1. Calibration - Ball drop method.

Mean impact force is calculated from the following formula based on the impulse-momentum theorem

$$
F_{\text {mean }}=\frac{1}{\tau} \int_{t_{1}}^{t_{2}} F(t) d t=\frac{m}{\tau}\left(v_{1}+v_{2}\right) .
$$

Velocities before and after the impact are calculated from the following formula

$$
v_{1,2}=\sqrt{2 g h_{1,2}}
$$

where $h_{1,2}$ are heights and $g$ is gravity acceleration. Maximum force is double of the mean force, which results from the shape of the measured signal

$$
F_{\text {max }}=2 \cdot F_{\text {mean }}
$$

\section{Experimental setup}

In this study a $28 \mu \mathrm{m}$ thick PVDF film transducer (DT1$028 \mathrm{~K} / \mathrm{L}$ ) manufactured by TE Connectivity was chosen. The active area of a $12 \mathrm{~mm}$ x $30 \mathrm{~mm}$ of the transducer was reduced to $12 \mathrm{~mm} \times 1,5 \mathrm{~mm}$ (dimensions $b \times c$ in Fig. 2.). Transducers were placed in a machined holes of aluminium blocks. The protective layers thicknesses were $1 \mathrm{~mm}, 1,5 \mathrm{~mm}$ and $2 \mathrm{~mm}$ (dimension $a$ in Fig. 2.). The mounting procedure included a gluing of the active transducer area by a cyanoacrylate glue (Loctite Super Attak Power Flex Gel), the casting of the hole by a transparent two component epoxy glue (Bison $5 \mathrm{~min}$ ) and a grinding and polishing the upper surface.

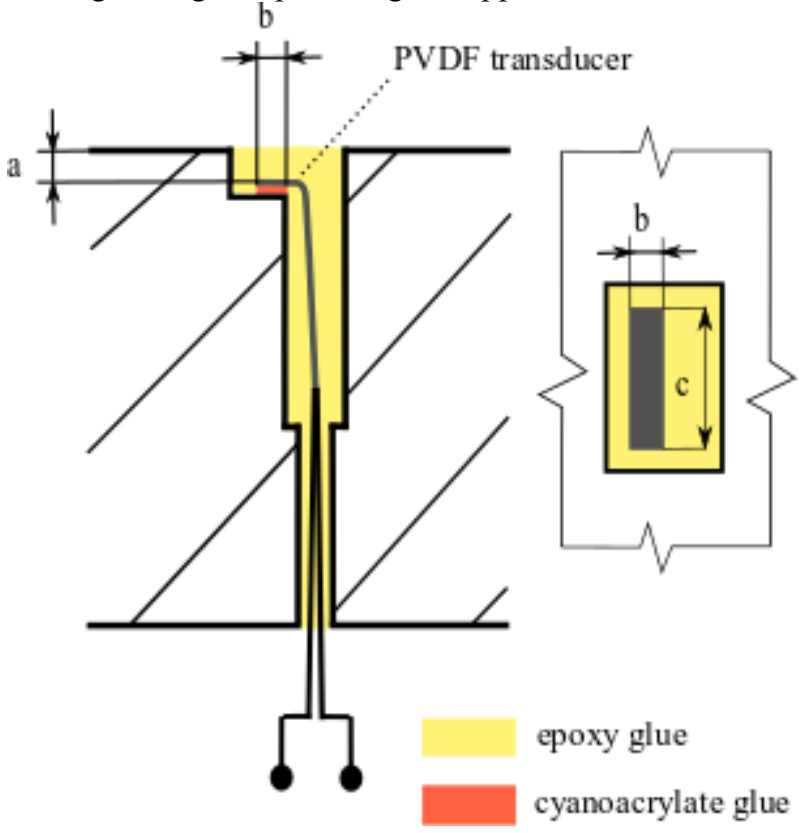

Fig. 2. Mounting of the PVDF transducer.

The transducer was connected directly to the NI USB 5132 digitizer input, which was used for the signal acquisition (Fig. 3.). Signals were analysed in LabVIEW Signal Express software, where the impact duration $\tau$ and maximum voltage $U_{\max }$ were detected. The digitizer, computer, aluminium blocks and negative pole of PVDF transducer were grounded to avoid a signal noise (Fig. 3.).

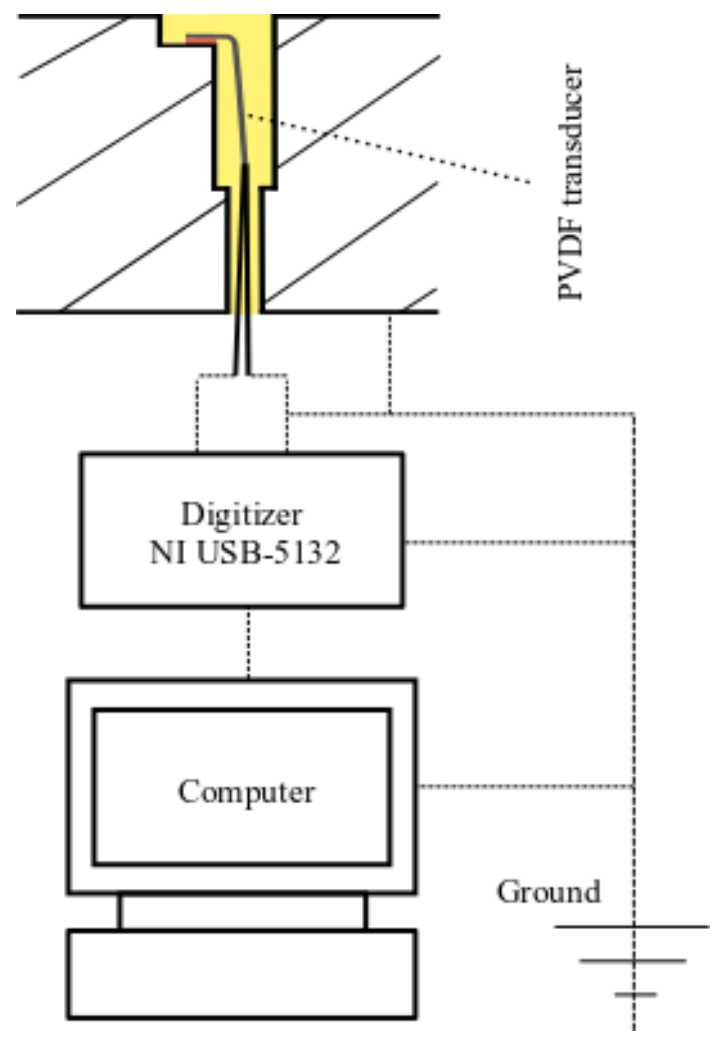

Fig. 3. Experimental setup. 
Five different stainless steel balls (mass: $0,44 \mathrm{~g} ; 0,7 \mathrm{~g}$; $1,046 \mathrm{~g} ; 1,398 \mathrm{~g} ; 2,04 \mathrm{~g}$ ) were used for the measurement. Total number of tests for each protective layer thickness were 25. Initial position of the ball was defined by the length of guiding tube of $400 \mathrm{~mm}$ for all tests.

In Fig. 4. an example of the calibration signal for $1,5 \mathrm{~mm}$ protective layer thickness with ball of $0.7 \mathrm{~g}$ is presented. Maximum measured voltage in this case was $1,91 \mathrm{~V}$ and pulse duration was $53 \mu \mathrm{s}$.

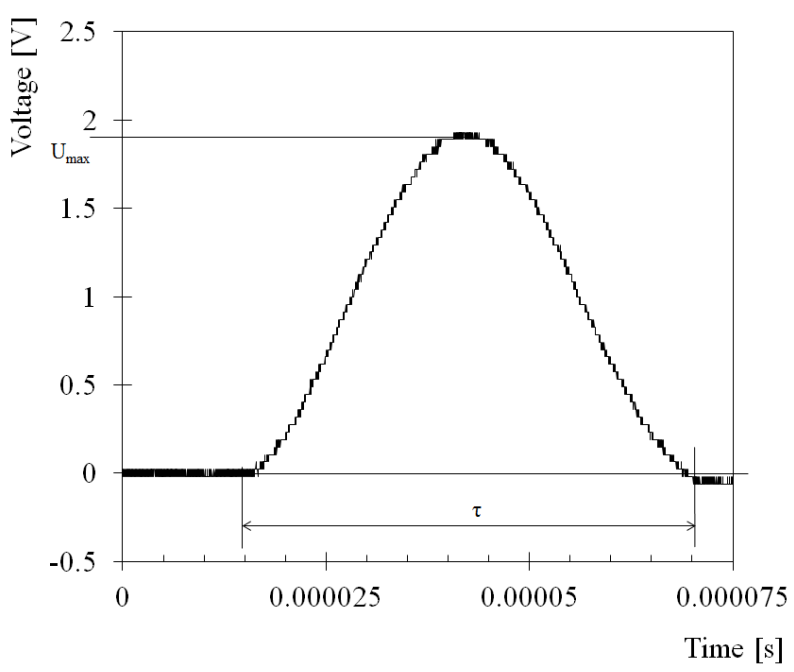

Fig. 4. An example of a calibration signal (ball $0,7 \mathrm{~g}$; tube $400 \mathrm{~mm})$.

\section{Results}

The results of the measurements are presented in Fig. 5. - Fig. 7. The linear least square method was used to fit the measured data. The sensitivity constants for $1 \mathrm{~mm}, 1,5 \mathrm{~mm}$ and $2 \mathrm{~mm}$ thick protective layer are $0,0156 \mathrm{~V} / \mathrm{N}, 0,0136 \mathrm{~V} / \mathrm{N}$ and $0,0115 \mathrm{~V} / \mathrm{N}$ respectively. Fig. 8. shows the sensitivity decrease with the increasing the protective layer thickness. The approximation method usually results in a nonzero voltage at the zero force, which is physically not possible. For this reason the zero voltage value was artificially added to the zero force for the fitting procedure.

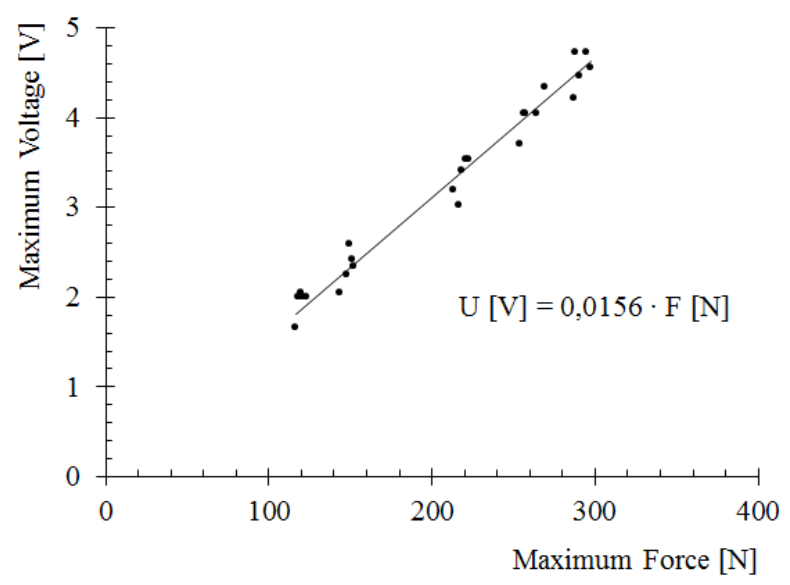

Fig. 5. The calibration $-1 \mathrm{~mm}$ thick protective layer.

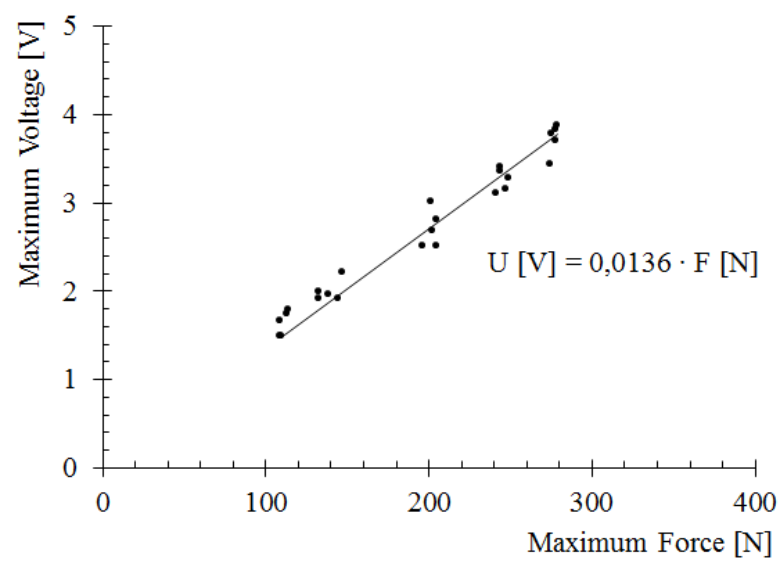

Fig. 6. The calibration $-1,5 \mathrm{~mm}$ thick protective layer.

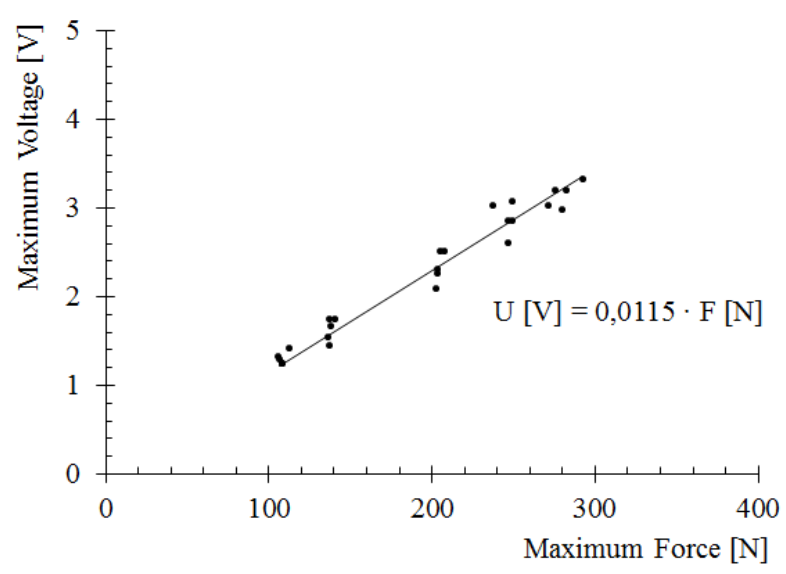

Fig. 7. The calibration $-2 \mathrm{~mm}$ thick protective layer.

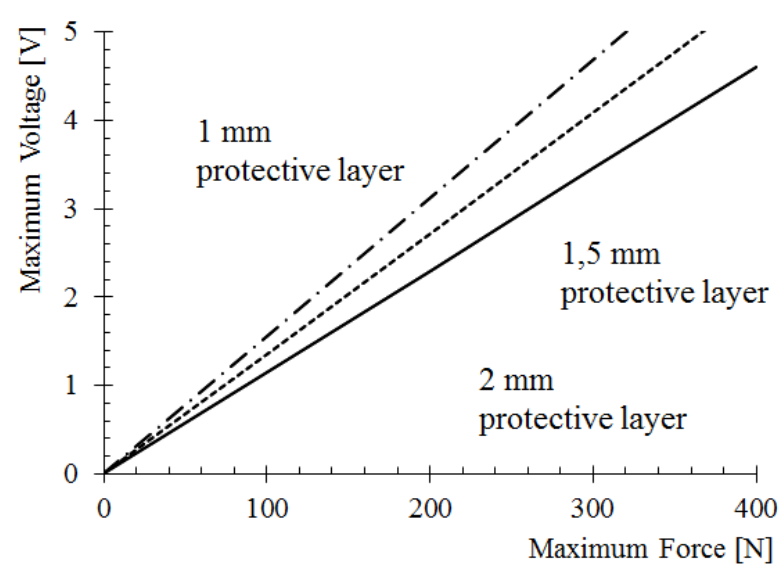

Fig. 8. The calibration curves recalculated according to measured calibration constants.

\section{Conclusion}

This work presents influence of the thickness of the protective layer for PVDF film transducers. It was shown that the presence of protective layer decreases the PVDF 
film sensitivity. From the practical point of view this means, that a new calibration should be required for each sensor mounting. The thickness of the protective layer also defines the possible duration of the measurement.

The results shows, that the maximum force dependence is almost linear and the calibration constants can be extended outside the calibration range.

\section{Acknowledgements}

This publication was written at the Technical University of Liberec as part of the project SGS no. 21182 "The cavitation phenomenon and its erosion potential" with the support of the Specific University Research Grant, as provided by the Ministry of Education, Youth and Sports of the Czech Republic in the year 2017.

\section{References}

1. K.H. Kim, G. Chahine, J.-P. Franc, A.Karimi, Advanced experimental and numerical techniques for cavitation erosion prediction (Springer, Dordrecht, 2014)

2. Ch.E. Brennen, Cavitation and Bubble Dynamics (Oxford University Press, Oxford, 1995)

3. T. Momma, A. Lichtarowicz, Wear 186-187, 425$436(1995)$

4. H. Soyama, Y. Sekine, K. Saito, Measurement 44, 1279-1283 (2011)

5. Y.Ch. Wang, Y.W. Chen, Experimental Thermal and Fluid Science 32 2, 403-414 (2007)

6. A.S. Grinspan, R. Gnanamoorthy, Colloids and Surfaces A: Physicochem. Eng. Aspects 356, 162168 (2010)

7. H. Soyama, A. Lichtarowicz, T. Momma, E.J. Williams, J. Fluids Eng. 120 (4), 712-718 (1998) 